$$
\text { "princz" — 2006/6/22 — 18:50 — page } 153 \text { - \#1 }
$$

\title{
A survey on how students seek information on the internet
}

\author{
Mária Krausz-Princz
}

\begin{abstract}
Navigating among the information available on the Internet has become an expectation for the members of the information society we are living in. This especially applies to students of higher education, the intellectuals of the future. It is a general experience that most users make one or two word searches and they don't know about the possibilities offered by various search engines, which can make searches more effective. Given results from abroad we have set up a study among the students of the University of Debrecen (UD) about their use of the Internet, their knowledge of searching strategies and techniques, their perceptions of the effectiveness and efficiency of search engines. This paper reports the results of this study. The results imply that it is imperative that area should be included in the curriculum.
\end{abstract}

Key words and phrases: Internet, searching, search engines, search strategies and techniques, user attitudes, invisible web.

ZDM Subject Classification: Q90.

\section{Introduction}

There are a large number of papers discussing users' searching strategies and behaviour $[1,4,5,6,7,8,9,10]$. The numerical figures showing users' general Internet using behaviour can be found in the analyses of the marketing company iProspect $[2,3]$. A Canadian study [4] undertaken among $12^{\text {th }}$ grade high school students in New-Scotland examining their Internet searching skills was of special interest to us. The study examines the information locating strategies and techniques of 198 high school students (their average age being 17.5 years) as well

Copyright (c) 2006 by University of Debrecen 


$$
\text { "princz" — 2006/6/22 — 18:50 — page } 154 \text { — \#2 }
$$

as seeking to answer questions like how familiar students are with various Internet search engines, how they perceive their own information locating capabilities and how they learnt them.

Reading studies on the topic we have become interested in how our students perform: how they can navigate on the web, in what ways and how effectively they search. We were seeking to answer the following questions in connection with the students' knowledge of information location:

(1) What Internet services do the students use and how often?

(2) What information sources do they prefer in their study related assignments next to their textbooks?

(3) How do they perceive their own ability to locate information on the Internet?

(4) What Internet access possibilities do students have?

(5) How do students learn to seek information on the Internet?

(6) What knowledge do students have of the various Internet search engines?

(7) What strategies and techniques do students use to enhance information seeking on the Internet?

(8) What influences students' search abilities?

(9) What searching habits do students have?

(10) How do they rate the effectiveness of search engines?

In order to answer these questions we developed a questionnaire consisting of 21 questions, which in part coincide with those studied in the papers of Gunn \& Hepburn [4] and Greenspan [2]. When interpreting the answers given to our questions in the case where the questions are the same we also compare our results with those reported in the papers above.

The questionnaires were preliminarily tested at two faculties of the University of Debrecen, at the Faculty of Engineering and the Faculty of General Medicine. The modified and extended questionnaire was then, in spring 2005, answered by 200 full time students of the University of Debrecen representative of the ratio of the number of students at the faculties. The students were mostly from the lower years.

To increase our sampling-rate we are planning to make our questionnaire available on-line.

To analyse the answers we used the table manager Excel and the statistical software SPSS. 


\section{Results}

We analyse the answers in the order of the questions of the questionnaire.

1. What Internet services do the students use and how often?

Table 1 shows the services used by students relative to the number of students.

Table 1. Internet services used in the different faculties.

\begin{tabular}{|l|r|r|r|r|r|}
\hline \multicolumn{1}{|c|}{ Faculties } & WWW & E-mail & Ftp & Telnet & Chat \\
\hline Faculty of Law & $100 \%$ & $100 \%$ & $0 \%$ & $0 \%$ & $11 \%$ \\
\hline Faculty of Medicine & $95 \%$ & $74 \%$ & $16 \%$ & $0 \%$ & $32 \%$ \\
\hline $\begin{array}{l}\text { Faculty of Agricultural } \\
\text { Economics and Rural } \\
\text { Development }\end{array}$ & $100 \%$ & $73 \%$ & $0 \%$ & $0 \%$ & $40 \%$ \\
\hline Faculty of Humanities & $97 \%$ & $94 \%$ & $8 \%$ & $0 \%$ & $36 \%$ \\
\hline College of Music & $100 \%$ & $50 \%$ & $0 \%$ & $0 \%$ & $50 \%$ \\
\hline Health Collage Faculty & $100 \%$ & $88 \%$ & $13 \%$ & $0 \%$ & $19 \%$ \\
\hline Faculty of Dentistry & $100 \%$ & $67 \%$ & $0 \%$ & $0 \%$ & $33 \%$ \\
\hline Faculty of Pharmacy & $100 \%$ & $100 \%$ & $0 \%$ & $0 \%$ & $33 \%$ \\
\hline Faculty of Education & $100 \%$ & $75 \%$ & $0 \%$ & $0 \%$ & $13 \%$ \\
\hline Faculty of Informatics & $100 \%$ & $91 \%$ & $82 \%$ & $36 \%$ & $9 \%$ \\
\hline $\begin{array}{l}\text { Faculty of Economics and } \\
\text { Business Administration }\end{array}$ & $100 \%$ & $100 \%$ & $10 \%$ & $0 \%$ & $30 \%$ \\
\hline Faculty of Technical Engineering & $100 \%$ & $89 \%$ & $32 \%$ & $0 \%$ & $26 \%$ \\
\hline Faculty of Agriculture & $100 \%$ & $67 \%$ & $7 \%$ & $0 \%$ & $33 \%$ \\
\hline Faculty of Science & $100 \%$ & $91 \%$ & $9 \%$ & $3 \%$ & $32 \%$ \\
\hline Sum total & $\mathbf{9 9 \%}$ & $\mathbf{8 6 \%}$ & $\mathbf{1 4 \%}$ & $\mathbf{3 \%}$ & $\mathbf{2 9 \%}$ \\
\hline
\end{tabular}

The great majority of the students use the Internet for locating information as well. $32 \%$ of the students use the internet regularly, $65 \%$ occasionally, to collect information, material for their studies, while $44 \%$ regularly and $55 \%$ occasionally searches the World Wide Web for personal purposes. 
2. What information sources do students prefer in their study related assignments next to their textbooks?

The following table shows the answers they gave:

Table 2. Use of information sources.

\begin{tabular}{|l|r|}
\hline Web & $11.60 \%$ \\
\hline print sources & $34.20 \%$ \\
\hline Equally & $52.80 \%$ \\
\hline none of them & $1.50 \%$ \\
\hline
\end{tabular}

Many students prefer the Internet to books when searching for study related information [6, 7]. Canadian schools have been increasing their spending on the Internet and at the same time have dramatically decreased that of on print sources [4]. Most students at the University of Debrecen equally are in favour of the World Wide Web and books, but all in all there is a majority of those who prefer print sources in addition to textbooks. We find this fact a bit surprising as textbooks contain the course material, while the corresponding research results are mostly available on the World Wide Web first: it takes a considerably longer time to publish print material than publishing on the World Wide Web, and due to the limited financial resources many print materials aren't available in the libraries of the institutions.

3. How do students perceive their own ability to locate information on the Internet?

The questions concerning the self-assessment of their searching abilities were wilfully placed before the questions concerning searching strategies and techniques.

Table 3. Students' perception of their own searching abilities.

\begin{tabular}{|l|l|}
\hline Poor & $10.5 \%$ \\
\hline Fair & $56.8 \%$ \\
\hline Good & $32.7 \%$ \\
\hline
\end{tabular}

Although most students use few effective strategies when searching World Wide Web for information and use even fewer services to limit and refine the 


$$
\text { "princz" — 2006/6/22 — 18:50 — page } 157 \text { — \#5 }
$$

search results they consider their searching abilities to be average or good. Positive self assessment is even more obvious with Canadian students, where $5.1 \%$ consider themselves weak, $13.6 \%$ average and $81.3 \%$ good or very good at searching, while their results don't confirm this.

4. What Internet access possibilities do students have?

Having access to the Internet is a primary condition for the documents available there to become valuable sources of information.

We asked questions separately about Internet availability at work and at home. To the question 'Are there computers connected to the Internet available for you in your educational institution?' $79 \%$ of the students answered yes, $19 \%$ said with limitations, $2 \%$ replied no. These answers suggest that most students have opportunity to locate information on the Internet.

To the question 'Do you have access to the Internet at home?' $49.5 \%$ of the students answered yes, $50 \%$ said no, and 1 student didn't answer the question. In Greenspan's survey $72.7 \%$ of the students reported that they had Internet connection at home and only $27.3 \%$ replied no.

\section{How do students learn to seek information on the Internet?}

The question 'Who did you learn to search the Internet from?' allowed students to give more answers. ${ }^{1}$

Table 4. How do students learn to seek information on the Internet?

\begin{tabular}{|l|r|}
\hline teacher & $21 \%$ \\
\hline parent / family member & $12 \%$ \\
\hline friend / classmate & $44 \%$ \\
\hline myself & $60 \%$ \\
\hline all & $\mathbf{1 3 7 \%}$ \\
\hline
\end{tabular}

Most students involved in the survey (60\% of all the answers) reported that they learnt it by themselves, just like in the case of Canadian students, where this ratio is $72 \%$. The second most frequent answer among the students of the University of Debrecen was that it was a friend or a classmate, approximately

${ }^{1}$ This question allowed for more answers, that is, why the percentages don't add up to $100 \%$.
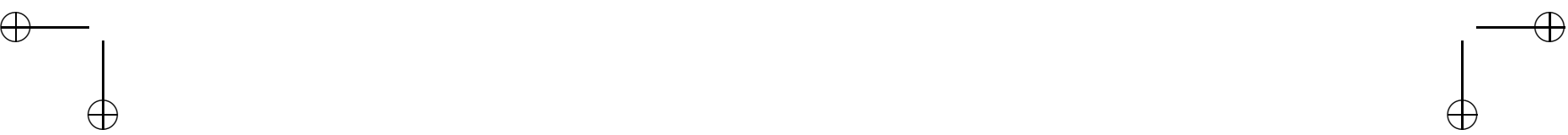
twice as many as the number of those who reported a teacher to be the source, which came third in the list. In the Canadian study the order is similar, with the difference that the answers friend/classmate and the answer teacher were equally frequent (being $39.3 \%$ and $39.8 \%$, respectively). In both surveys the family had the least role in learning searching techniques. The results of the surveys show that students rely mostly on themselves and their mates when learning how to locate information on the World Wide Web, and teachers have a less important role.

6. What knowledge do students have of the various Internet search engines?

There are firms that evaluate search engines from various aspects. One of these aspects is which search engine is most often used when making a search. According to the surveys of comScore Media Metrix in December 2004 and Nielsen NetRatings in March 2005 in the USA [1] Google comes first and is then followed by Yahoo and MSN in both surveys. In addition to these providers in each European country some national provider takes one of the three first places [1]. In Hungary the most popular search engine is Vizsla by Origo, but Heuréka and Góliát are also widely used in the country.

Table 5. The popularity and use of search engines among the students of the University of Debrecen.

\begin{tabular}{|l|c|c|c|}
\hline Search Engines & $\begin{array}{c}\text { Never heard } \\
\text { of it }\end{array}$ & $\begin{array}{c}\text { Used it } \\
\text { occasionally }\end{array}$ & $\begin{array}{c}\text { Used it } \\
\text { regularly }\end{array}$ \\
\hline AlltheWeb & $94.0 \%$ & $3.0 \%$ & $0.5 \%$ \\
AltaVista & $24.5 \%$ & $38.0 \%$ & $7.0 \%$ \\
AskJeves & $98.0 \%$ & $0.0 \%$ & $0.0 \%$ \\
Góliát & $61.0 \%$ & $15.5 \%$ & $3.0 \%$ \\
Google & $3.0 \%$ & $35.0 \%$ & $62.0 \%$ \\
Heuréka & $40.5 \%$ & $22.0 \%$ & $4.0 \%$ \\
Lycos & $86.0 \%$ & $4.0 \%$ & $0.0 \%$ \\
MSN & $50.5 \%$ & $18.0 \%$ & $8.5 \%$ \\
Teoma & $97.5 \%$ & $0.0 \%$ & $0.0 \%$ \\
Vizsla & $15.0 \%$ & $49.0 \%$ & $11.5 \%$ \\
Yahoo & $12.5 \%$ & $50.5 \%$ & $16.0 \%$ \\
\hline
\end{tabular}


The providers in our survey were chosen on the basis of their former and present popularity and the size of their indexed material. Three Hungarian search engines were also included in our survey.

The result we got from the sample representing the ratio of students studying at various faculties of the University of Debrecen is shown in the Table 5.

The 3 most popular search engines in the USA are among the best-known among the students, but AltaVista and Lycos, which were formerly so popular, are also well known. There is no correspondence between the size of the indexed material and popularity or familiarity, since the second and fourth top rate engines by size, AlltheWeb and Teoma, are not among the most popular search engines either in the USA or in Canada and the students of the University of Debrecen are only minimally familiar with them. Ask Jeeves, which is popular among American and Canadian high school students, is fairly unknown among our students. The most popular search engine in Hungarian is Vizsla (with 85\%), then come Heuréka and Góliát.

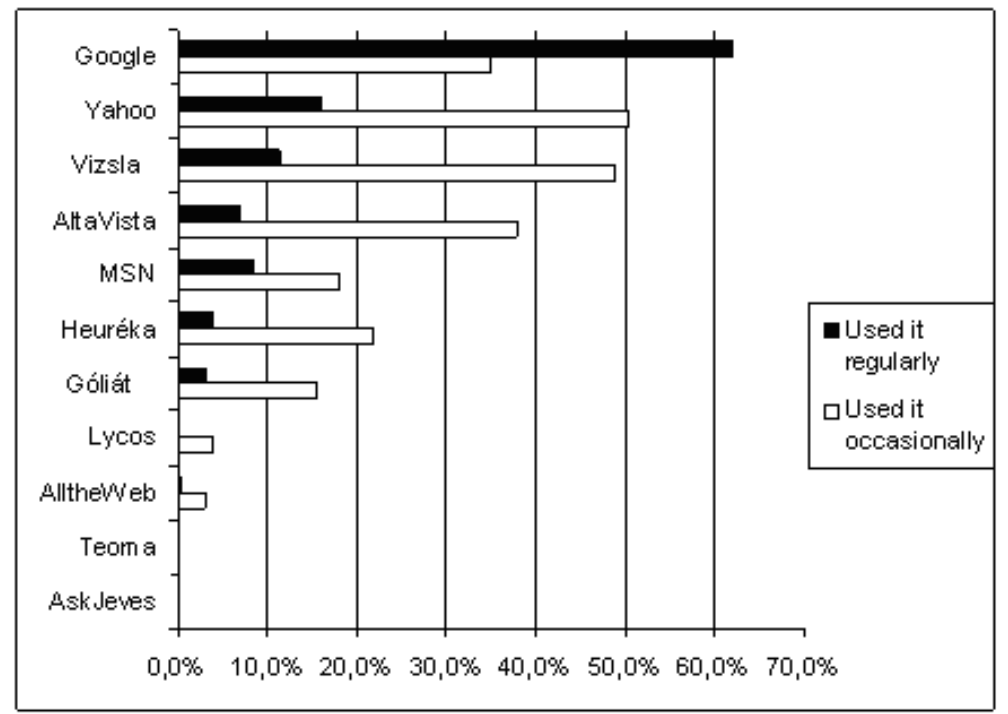

Chart 1. The use of the most popular search engines among the students of UD.

According to our survey students use on the average 3-4 search engines regularly or occasionally. This number is higher, than the corresponding one in the Canadian survey, where this number is 1-2 among high-school students. 
Chart 1 shows the most frequently used, that is, the most popular search engines among the students of UD. Since students could choose more than one engine and we gave the percentage relative to all Occasionally chosen and all Regularly chosen, so the percentages don't add up to 100. Google is by far the most popular among the students: $62 \%$ uses it regularly, and the ratio is similar among Canadian students, i.e., $66.7 \%$.

Students were asked to name the search engine or other starting point they most often use, if it is not listed in the survey. Apart from the ones included in the survey they mentioned 4 providers in 11 cases: Startlap (3\%), Kurzor (1\%), Keresőlap (1\%), Kapu (0.5\%).

7. What strategies and techniques do students use to help information seeking on the Internet?

The findings of our survey can be seen in Table 6 .

Table 6. The use recommended searching strategies among the students of UD.

\begin{tabular}{|l|c|c|c|}
\hline & $\begin{array}{c}\text { Never used these } \\
\text { or didn't answer }\end{array}$ & $\begin{array}{c}\text { Used } \\
\text { occasionally }\end{array}$ & $\begin{array}{c}\text { Used } \\
\text { often }\end{array}$ \\
\hline $\begin{array}{l}\text { Use of Boolean operators } \\
\text { (AND, OR, NOT) }\end{array}$ & $76.0 \%$ & $19.5 \%$ & $4.5 \%$ \\
\hline $\begin{array}{l}\text { Use of + to join words or } \\
- \text { to remove words }\end{array}$ & $80.0 \%$ & $15.5 \%$ & $4.5 \%$ \\
\hline $\begin{array}{l}\text { Use of " " to search as a } \\
\text { phrase }\end{array}$ & $53.5 \%$ & $36.5 \%$ & $10.0 \%$ \\
\hline Use of a wildcard & $65.5 \%$ & $29.0 \%$ & $5.5 \%$ \\
\hline Use of advanced search & $64.0 \%$ & $28.5 \%$ & $7.5 \%$ \\
\hline
\end{tabular}

The use of Boolean operators is an effective tool for improving the search results of free word search engines $[1,11,12]$. More than three fourths of the students don't use Boolean operators or the simpler operators +, - either, and this ratio is higher than in Canada.

Searching for expressions limits the results, too. This possibility was best known and used among the students of UD, but the ratio of those who use it regularly or occasionally didn't reach $50 \%$, which is less than that for Canadian students. 
Wildcards at the end of words can be used to stand for plurals or endings, but some engines also use them inside the word to allow for various spelling possibilities. The students at UD showed a better result than the Canadians in this question: $37 \%$ reported that occasionally or regularly they use joker characters, while the ratio among Canadian students was $9 \%$.

When formulating a request, almost every engine offers the possibility of advanced search, where there is no need to use logic operators, it is enough to write the search words into various boxes to define the logical relationships between them, or to filter the results in various ways. Only a few people use the advanced search window, because either they do not notice the link, or they do not know what it means, or they do not take the time and attention to try it. Most students at UD answered no when we asked whether they used this possibility or not. This ratio is even worse among the Canadian students: $82.3 \%$ answered no, $10.1 \%$ answered occasionally and only $7.6 \%$ uses it regularly.

Strategies recommended for effective information location on the Internet are accompanied by various techniques to limit and refine the results or focus them on a certain area. When asking about these techniques, we received the following answers:

Table \%. Knowledge of techniques for limiting and refining search results.

\begin{tabular}{|l|c|c|}
\hline & Yes & No \\
\hline $\begin{array}{l}\text { Do you know how to eliminate } \\
\text { commercial sites when you search? }\end{array}$ & $1.5 \%$ & $98.5 \%$ \\
\hline $\begin{array}{l}\text { Do you know how to limit search to } \\
\text { pages updated in last three months? }\end{array}$ & $7.0 \%$ & $93.0 \%$ \\
\hline $\begin{array}{l}\text { Do you know how to limit search to } \\
\text { title section of a Web page? }\end{array}$ & $7.5 \%$ & $92.5 \%$ \\
\hline $\begin{array}{l}\text { Do you use any particular feature for } \\
\text { a file type (image, sound) search? }\end{array}$ & $28.0 \%$ & $72.0 \%$ \\
\hline
\end{tabular}

Eliminating . com sites can be a very useful searching technique if you want to find school related information and fresh research results in the English language, but in other cases as well, it might be useful to eliminate certain web servers. It applies especially to those fields where commercial products and web sites make up most of the search results. 
"princz" — 2006/6/22 — 18:50 — page 162 - \#10

It can also be found useful to give the site or domain on which to search (e.g. when wanting to locate information on a university's pages).

Students showed great ignorance concerning these techniques: $98.5 \%$ gave a negative answer, while it was only $77.8 \%$ among the Canadian students. The reason for the $20 \%$ difference could be that eliminating . com sites does not exclude Hungarian commercial sites, and thus, students here rarely use this option.

A similar result was found regarding the knowledge of techniques limiting the search to a given time interval (e.g. the last 3 months, half year, year etc.) and to certain parts of the document (e.g. website address, references etc.). $93 \%$ and $92.5 \%$ of the students did not know these techniques, while the results among Canadian students were $72.7 \%$ and $85.4 \%$, respectively.

The best results were shown in the knowledge of services facilitating various types of information (e.g. picture, sound, etc.). The ratio of negative answers was $72 \%$, which is only a little bit more than the $70.7 \%$ in Canada.

\section{What influences students' search abilities?}

When analysing our survey we would have liked to answer the question what students' searching abilities depend on, more precisely if it is influenced by the student's sex, their interest in computer science, their access to the Internet or at which faculty they study.

To measure their searching capabilities their answers given to the questions concerning various searching strategies and techniques were included in one single variable using factor analysis and we studied the dependence of this variable under certain conditions.

According to [4] searching ability is influenced by having access to the Internet at home, since - their results show - those students who have access to the Internet at home use the various search techniques more often. They also found that the majority of students who can use the Internet at home learn to search mostly on their own and less from their teachers or classmates than those, who have no Internet access in their homes. Those with Internet in their homes consider their searching abilities to be better than those, who do not have that. These two latter statements - to a less extent, though - are also confirmed by our findings.

Based on the answers of the students we could not statistically find a significant correspondence between access to the Internet (either at home or in the educational institution) and searching abilities. Statistical tests have shown, on the other hand, that searching abilities are influenced by the interest in computer science. 


$$
\text { "princz" — 2006/6/22 — 18:50 — page } 163 \text { — \#11 }
$$

Various tests have shown a correlation between the students' sex and their searching abilities, but further investigations (two-conditional variation analysis) have proved that sex influences searching abilities through the interest in computer science, but on its own, it is independent from it. We have come to the same conclusion examining the searching abilities of students studying at the various faculties: there was a significant difference in results among the students studying at the Faculty of Informatics and the students studying at the other faculties.

9. What searching habits do students have?

When investigating user habits while searching the World Wide Web one of the issues were how many search engines they use. While American and Canadian users are loyal to one or two search engines, students at UD - as it has been discussed in question 6 - mainly use 3 or 4 engines.

When asked the question 'What do you do when the first search fails?' $85 \%$ answered that they refine the searching request; $11.5 \%$ try another search engine; $3.5 \%$ stops searching. Although our students normally use more search engines, after the first failure fewer students try another one than those in Greenspan's survey in 2002 , where this ratio is $27.5 \%$. Given the results of question 7 , it is likely that refining the search request for students does not mean the use of various limiting and refining possibilities, but giving further or maybe more searching keywords.

To the question concerning scanning the search results $4 \%$ of the students answered that they only have a look at the first one or two results, $30.5 \%$ scans the first result page, $65.5 \%$ scans more result pages. Greenspan's survey presents these ratios to be $16 \%, 32 \%$ and $52 \%$ respectively.

The survey [3] finds that women are less careful at scanning the results since the ratio of those stopping the search is $15.2 \%$ more among women than among men. In our survey this ratio is $8 \%$.

Table 8. Scanning search results among males and females.

\begin{tabular}{|l|c|c|}
\hline & male & female \\
\hline review only the first few results & $3 \%$ & $4 \%$ \\
\hline view the entire first page & $26 \%$ & $33 \%$ \\
\hline review further result pages & $71 \%$ & $63 \%$ \\
\hline
\end{tabular}




$$
\text { "princz" — 2006/6/22 — 18:50 — page } 164 \text { — \#12 }
$$

10. How do students rate the effectiveness of search engines, do they know the concept of invisible web?

At the end of the questionnaire we asked the students that how many percent of all the documents on the web they think the best search engines seek in. This question was intended to drive at the notion of invisible web, since the answers implied a trust in search engines, that they index the majority of information available on the web.

The first survey [13] investigating the coverage of the web showed that the then best HotBot indexed only $34 \%$ of the web, and this ratio is getting worse and worse with the growth of the web. If we include online databases, intranet files and all that belongs to what is considered invisible web, then the documents indexed by even the best search engine make up only a small fragment of all that's available on the web.

The estimates, given by students at the various faculties regarding the size of indexed web sites, ranged from $48 \%$ to $72 \%$, which gives an average of $64 \%$ at the university. These are very high percentages and they show an overestimation of search engines.

\section{Summary}

The knowledge of what search facilitating tools are available on the web and when and how to use them can make information seeking more effective and powerful.

In addition to choosing the right search engine it is also important to be familiar with its features, how to formulate the search request since all these influence the result set.

Knowing the features of search engines helps not only with formulating the right request, but it also helps with developing easily searchable web sites.

Experience shows that most students do not know what possibilities there have when seeking for information: they do not use advanced searches and they are not familiar with the possibilities of advanced search.

The results of the survey imply the conclusion that teaching of various searching strategies should be included in the school curriculum to increase students' awareness of searching tools. It takes only a few lessons to introduce searching strategies and techniques to limit and refine search results. If lack of time does 


$$
\text { "princz" — 2006/6/22 — 18:50 — page 165 — \#13 }
$$

not make it possible, students' attention should be drawn to the possibility of advanced search. Once they learn that there is a window where they get considerable help for their search, then they will hopefully explore these tools.

\section{References}

[1] Search Engine Watch, http://searchenginewatch.com.

[2] R. Greenspan, Search Engine Usage Ranks, Cyberatlas, November 14, 2002.

[3] iProspect, Search Engine User Attitudes Survey April-May 2004, http://www.iprospect.com.

[4] H. Gunn, G. Hepburn, Seeking Information for School Purposes on the Internet, Canadian Journal of Learning and Technology 29, no. 1 (2003).

[5] J. Nielsen, Search: Visible and Simple, Alertbox, May 13, 2001, http://useit.com.

[6] Environics Research Group, Young Canadians in a wired world: the students' view, Report prepared for the Media Awareness Network and the Government of Canada. Retrieved Nov. 2001, http://www.media-awareness.ca.

[7] D. Bilal, Children's use of Yahooligans! Web Search Engine: 1. Cognitive, physical, and affective behaviours on fact-based search tasks, Journal of the American Society for Information Science 51, no. 7 (2000).

[8] J. Griffiths, P. Brophy, Student searching behaviour in the JISC Information Environment 2002, http://www.ariadne.ac.uk/issue33/edner.

[9] G. Thórsteinsdóttir, Information-seeking behaviour of distance learning students, Information Research 6, no. 2 (January 2001).

[10] Information Seeking Behaviour, http://www.librarysupportstaff . com/infoseek.html.

[11] D. Sullivan, Search engine math, Search Engine Watch (November 22, 2001), http://searchenginewatch.com/facts/math.html.

[12] Recommended Sites and Search Techniques, http://library.albany.edu/internet/search.html.

[13] S. Lawrence, L. Giles, Searching the World Wide Web, Science (1998).

MÁRIA KRAUSZ-PRINCZ

UNIVERSITY OF DEBRECEN

FACULTY OF TECHNICAL ENGINEERING

H-4024 DEBRECEN

ÓTEMETÖ U. $2-4$

HUNGARY

E-mail: pmaria@delfin.unideb.hu

(Received November, 2005) 